\section{Política y Sociedad}

ISSN-e: 1988-3129

\title{
Municipalismo como radicalización democrática del territorio. Un análisis histórico crítico de experiencias contemporáneas de gobernanza local
}

\author{
Alejandro Caamaño López ${ }^{1}$
}

Recibido: 07-05-2021 // Aceptado: 22-10-2021

Resumen. La crisis económica de 2008 ha generado una crisis orgánica que cuestiona las bases del régimen constitucional de 1978, enraizado en una lógica autoritaria del Estado español del xix y el absolutismo, que nunca ha abandonado. Ha dado lugar a iniciativas políticas de carácter municipalista con raíz inmediata en movilizaciones sociales originadas en el 15M, y diversos procesos de movilización social, como el llamado procés. El objetivo general de esta investigación consistirá en una interpretación crítica fundamentada en los principios de la economía política crítica disruptiva donde presentar el génesis de la lógica municipalista. Para ello, nos centraremos en el análisis de estas propuestas que han llegado a constituir actores determinantes en la constitución de nuevos gobiernos locales, a través de la revisión y selección de referencias bibliográficas relativas al estudio de los distintos enfoques teóricos referentes al municipalismo.

Palabras clave: municipalismo; radicalización democrática; ecología social; glocal.

\section{[en] Municipalism as a democratic radicalization of the territory. A critical historical analysis of contemporary experiences of local governance}

\begin{abstract}
The economic crisis of 2008 has generated an organic crisis that questions the foundations of the constitutional regime of 1978, rooted in an authoritarian logic of the Spanish State of the 19th century and the absolutism that it has never abandoned, giving rise to political initiatives of a municipal nature with immediate roots in social mobilizations originated in the $15 \mathrm{M}$ and various processes of social mobilization such as the so-called procés. The general objective of this research will consist of a critical interpretation based on the principles of disruptive critical political economy where to present the genesis of the municipal logic. To do this, we will focus on the analysis of these proposals that have come to constitute determining actors in the constitution of new local governments through the review and selection of bibliographic references related to the study of the different theoretical approaches regarding municipalism.
\end{abstract}

Keywords: municipalism; democratic radicalization; social ecology; glocal.

Sumario: 1. Introducción. 2. Hipótesis y objetivos. 3. Metodología. 4. De la teoría a la práctica. 5. Conclusiones. 6. Bibliografía.

Como citar: Caamaño López, A. (2022). Municipalismo como radicalización democrática del territorio. Un análisis histórico crítico de experiencias contemporáneas de gobernanza local. Polit. Soc. (Madr.) 59(1), 75970. https://dx.doi. org/10.5209/poso. 75970

\section{Introducción}

\subsection{Crisis económica y crisis constituyente del modelo territorial}

El estallido de la burbuja inmobiliaria ocurrido en el Estado español se produjo en combinación con otros fenómenos económicos y políticos. Por un lado, acaeció la recesión económica desatada en 2008, a raíz de la crisis financiera producida tras la quiebra de Lehman Brothers. Los efectos de esta depresión se exacerbaron por la agresividad de las devenidas reformas de "austeridad" emprendidas por el Partido Popular desde su llegada al Gobierno, y por el notable incremento de la represión en términos deflacionarios del poder institucional clásico (Parsons, 1976), plasmada en la reforma de la ley penal relativa a la criminalización de la protesta. A estos factores hay que añadir el control de los mass media, cuyo eco se proyecta más allá de la investigación de políticas comparadas en artículos académicos cómo "Por qué la corrupción no se castiga" (Lapuente, 2012), 
hasta el actual caso popularmente denominado como "Las cloacas del Estado" o "La policía patriótica", que ahondan en una severa falta de independencia de los medios de comunicación y las administraciones públicas, que han conducido al Estado a una situación de emergencia.

Se evidencia una deflación de poder como una limitación de la capacidad de autogobierno real por parte del Gobierno central, sustituida por el control monopolístico de la violencia (Talcott, 1986). Hay una pérdida de apoyo a los partidos del régimen constitutivo (Linde Paniagua; 2014) que resulta palpable en el panorama catalán mediante estadísticas. Estas muestran cómo en el año 2014, un 95\% aproximado de la población catalana consideraba mala, o muy mala, la coyuntura política española, en comparación con el casi $65 \%$, que lo sostenía en 2007, fecha previa a la crisis inmobiliaria, según indican los registros del Centro de Estudios de Opinión de la Generalitat (CEO). Otro dato relevante era la insatisfacción general manifestada por casi un $85 \%$ de los encuestados respecto al funcionamiento de la democracia española, en comparación al $48 \%$ de 2007 , al igual que ocurría si se toma como referencia el 68'5\% registrado en el sondeo previo a las elecciones generales en España del 20 de noviembre de 2011. En él destacaban también unas valoraciones numéricas sobre el Gobierno de cuatro puntos o menos en una escala de $1 / 10$, en el $83 \%$ de los casos, según datos proporcionados por el CEO.

La rigidez de la actuación del Estado estructurada por medios judiciales con un trasfondo profundamente autoritario se conjuga con una crisis de régimen que ha acabado reforzando, por un lado, el descontento social generalizado y, por otro, la cristalización de una identidad catalana, que se consolida como mayoría social del $62 \%$ de la población (CEO, 2014). Se constata así la existencia de tendencias hacia nuevos marcos de identificación colectiva proclives a la soberanía catalana y autoubicada en un espectro político de izquierda. De ello resulta que la estructura del régimen constitutivo de 1978 pactada en la Transición queda de entredicho, creando una crisis de régimen, u orgánica, desde un enfoque gramsciano, y una deflación de poder creciente en términos territoriales en lo que se refiere a Cataluña y su proceso soberanista (Franzé, 2016). Encuentra sus bases en el llamado Estado de las autonomías, donde se consigue paz política a cambio de dotar de poder meramente administrativo a entidades territoriales que históricamente han reclamado soberanía propia (Fontana, 2014).

Hay un intento del PSOE de aprobar la LOAPA en 1982. Se pasa por la ofensiva recentralizadora iniciada en el 2000 por el Gobierno del Partido Popular de Aznar, con la impugnación del Partido Popular en 2007 a 30 artículos del Estatuto de Autonomía de Cataluña que están calcados en el Estatuto de Andalucía, y se termina por el marco de referencia antidescentralizador proyectado por la gran mayoría de los medios de comunicación de ámbito estatal desde 1978 (Linde Paniagua, 2014).

\subsection{Una redefinición de la idea misma de soberanía}

El motivo de lo anterior parece ser simple; atendiendo a la definición de Estado como la institución o conjunto de instituciones que ostentan un poder soberano sobre la producción de decisiones normativamente vinculantes (Weber, 1919), podemos afirmar que el concepto de Estado permanece asociado de forma intrínseca al concepto de soberanía. Esta definición del concepto otorgaría a la ciudadanía una autonomía inherente, lo cual serviría de base para la superación del lapsus constitucional de la Transición. De este modo se colmaría la ausencia de alternativa mediante la capacidad de decidir, a la vez que nos serviría para entender las posibilidades de alianza, puesto que no es más que un concepto equiparable al de poder, es decir, a la jurisdicción que uno tiene; en este caso, a la voluntad colectiva, de mandar o ejecutar un mandato (Subirats, 2019).

Atendiendo a estas definiciones, un Estado depositario del poder soberano debe gozar del poder de decidir pudiendo, por ende, poseer las competencias que permitan a este tomar decisiones sobre cuestiones tales como la economía. De no ser así, los intereses individuales, y de la empresa privada, toman relevancia sobre los derechos e intereses colectivos, creando un descontento generalizado, palpable en las mismas encuestas del CEO (2014). En ellas se refleja que un $82 \%$ de la población catalana considera que los políticos no tienen en cuenta los intereses populares, y cerca de un $79 \%$ cree que los dirigentes políticos solo piensan en su propio beneficio, a la vez que muestran cómo un $87^{\prime} 6 \%$ de la ciudadanía percibe el desarrollo de la economía de Cataluña mala o muy mala.

De este modo, se entiende que la cuestión nacional del proceso soberanista catalán — con un fuerte proceso catalizador mediático proyectado en los medios de comunicación nacionales en torno a las figuras de Artur Mas (2010-2016); posteriormente, alrededor del expresident de la Generalitat, Carles Puigdemont (2016-2017), y, seguidamente Quim Torra (2018-2020) — no puede ser desvinculada de la cuestión social. Esto permitiría comprender mejor el descontento del que el proceso hace acopio, proyectándose a la vez como una demanda de empoderamiento popular, y una demanda para recuperar las atribuciones soberanas que un conjunto de dispositivos institucionales puedan usar en pos de aplicar de forma autónoma sus decisiones, conformando un Estado social provisto de un sistema público de pensiones y una educación y sanidad públicas.

Cabe aquí ser cautelosos y precisos en el concepto de soberanía. Es un concepto moderno que nace a principios de la modernidad en una doble dimensión. Esta comprende la independencia de un Estado en sus relaciones y decisiones entre Estados y su jurisdicción territorial, como un principio cristalizado en la Paz de Westfalia o los Tractados de Müntser y Orsnabrück de 1648 y consolidado en el Tratado de Utrecht en 1713. 
Ha ido permutando históricamente desde su consolidación más absolutista bajo la premisa rex in regno suo est imperator regni sui, de aspiraciones hobbesianas, al actual y contemporáneo concepto de soberanía popular, que se enraíza en Masilio de Padua al Contrato Social de Rousseau (Mundó, 2019). Este lleva la soberanía a un punto más lejano: a la capacidad de participar en condiciones de igualdad en el proceso de toma de decisiones, como se entendería en un escueto concepto de libertad e igualdad liberal, a una forma de vida que atraviesa y cuestiona el concepto de democracia actualmente vigente (Noguera, 2019).

Este concepto se despliega tras el desplazamiento de las decisiones políticas y económicas tomadas en las instituciones representativas, con una escasa capacidad de incidencia en la esfera económica, tal como exponen las teóricas neopluralistas en la academia (Smith, 1994). Lleva a un empoderamiento de la ciudadanía en la toma directa de decisiones como una forma de vida, que se estructura en tres principios de soberanía paralelos e interconectados. 1) La soberanía superestructural, por la cual se resignifican y reestructuran las formas de organización política territorializadas; 2) la soberanía estructural, por la cual, las diversas culturas y sociedades recuperan el control y articulación del tiempo y el espacio como configuraciones socialmente construidas y, finalmente, 3) la soberanía individual enraizada en el derecho positivo como una forma comunitaria de libre asociación y organización social y económica (Noguera, 2019).

\subsection{El surgimiento de nuevos actores sociales y políticos}

No podemos obviar la evolución histórica concreta del Estado español, con una raíz absolutista longe durée consecuencia de treinta y seis años de dictadura y siete de un proceso de Transición gestado de manera vertical, sumados a casi dos siglos de construcción política convulsa e interrupciones bélicas (Anderson, 1979). De ahí se pasa a un proceso donde la disminución de la actividad industrial y el incremento de la tercerización económica social en España, tanto en relación al peso de los servicios dentro del PIB (Peñalosa, 2013) como a la parte de empleo que cada sector supone - exacerbada por su adhesión a la Comunidad Económica Europea en 1986 - daba el paso a una sociedad postindustrial. En esta, el auge y mejora del sentido subjetivo de seguridad económica y física producidos por la configuración de un Welfare State conforman el cambio a una sociedad postmaterialista, donde la escisión ideológica sobre la que se desarrolló el sistema de partidos se residualizaba; variando a su vez los cleavages sobre los que se fundamenta (Errejón, 2015).

En este punto, cabe atender el carácter postpolítico de la cultura política española contemporánea, donde se remplazaba el conflicto respecto visiones ideológicas antagónicas representadas en dos principales partidos que competían por el poder, en representación simbólica a las clases sociales participantes del conflicto civil de 1936, por un consenso generalizado de valores fundamentados en la realización personal en cuanto a libertad de expresión y de participación política (Mainer, 2006). Aun cuando estos valores se presentan como desprovistos de carga ideológica, que incluso así no logran remplazar el cleavage histórico social de la cultura política española, se ha conformado por ideas de carácter estrictamente materialistas reforzadas por la cristalización y consolidación de las desigualdades sociales. Ello ha dado cabida a la configuración de un nuevo cleavage que atiende, como se expresaba con anterioridad, a la deflación de poder y pérdida de apoyo a los partidos de régimen constitutivo a raíz de la crisis económica. En este mismo sentido, Jaime Pastor (2014: 225) recordaba siete tendencias críticas de evolución de la opinión pública en aquellos años:

La crisis de los partidos hegemónicos, el retraimiento ciudadano y la desafección electoral, la contradicción entre la evolución político-ideológica en la sociedad y el mapa de partidos, la aparición de nuevas potencialidades para un voto progresista (con una mayoría partidaria de una intervención activa del Estado en la economía y un alto respaldo social al $15 \mathrm{M}$ ), una desmesocratización y deterioro de las clases medias que apunta hacia una reconformación de las identidades de clase, una percepción crítica del aumento de las desigualdades (con una imagen oligárquica y oligarquizante de la actual conformación de la sociedad española y de los bancos como principal núcleo determinante del poder) y, finalmente, cambios identitarios y referenciales.

Este es un proceso crucial en el que se ponen de manifiesto las contradicciones entre la racionalidad histórico-política dominante, vinculada subjetivamente a la percepción de un sistema de oligarquía económicopolítica, y el devenir de nuevas conductas de carácter colectivo, vinculadas a nuevos sujetos políticos asociados a participación directa como símbolo de regeneración democrática. Es en este punto donde Joan Subirats (2015) plantea cómo, en el escenario configurado por la deflación de poder y pérdida de apoyo a los partidos de régimen constitutivo, se genera una concepción en torno a la política y a las formas de ejercer el poder. Esta retoma las perspectivas foucaultianas del poder entendido como algo flotante o circulante, emergente de una mayor participación social en la vida política desde la cotidianidad, que se gestiona en relación a los efectos que genera la población sobre los outputs institucionales, frente a la idea del poder como algo estático y vertical, retenido por las instituciones políticas, como era entendida hasta ahora en la política.

De esta forma, Xavier Domènech (2014) propuso hablar de "movimientos sociopolíticos" para ofrecer un marco explicativo de la acción colectiva desarrollada desde movimientos sociales que acababan convergiendo en plataformas ciudadanas para desarrollar la pelea más institucional, ante un sistema político que se había cerrado completamente a las demandas de los movimientos. Por ello nos encontraríamos ante movimientos 
sociopolíticos, en los que "la separación entre movimientos sociales y movimientos políticos, aunque guarde su lógica, también deviene en precaria" (Domènech, 2014: 33).

De esta nueva idea de entender la política emergen una amalgama de nuevos actores de carácter más conflictivo o rupturista, frente al comportamiento y ritmo adquiridos por un enfrentamiento sin acritud que el sistema bipartidista español había dado hasta ahora. En palabras de Josep Maria Atentas (2013: 72), se busca “"quitarse de encima' a los que mandan y de reemplazarlos por algo nuevo surgido desde fuera del sistema institucional convencional". Esto estaría vinculado con un proceso de politización de la sociedad española muy fuerte, que dejaría atrás el momento de "ilusión social" de creencia en la espontaneidad del movimiento por la necesidad de retomar la cuestión del poder. Atentas llamó a esto "efecto Syriza" (Atentas, 2013: 271).

En definitiva, parece claro que una nueva forma de entender la política se consolida, en palabras de Wallerstein (1997), en tiempos de bifurcación, como súmmum multisecular de las insostenibilidades planetarias y un desarrollo tecnológico que deviene un nuevo circuito de informaciones mediante las que se cuestionan las élites y sus agendas en un compartir global que demanda protagonismo social frente a la desafección provocada. Esta nos permitirá explicar el nacimiento de las propuestas de candidaturas municipalistas emergidas entre 2014 y 2015, como Ahora Madrid, Barcelona en Comú, Aranzadi Pamplona, y otras agrupaciones locales independientes de carácter crítico y asambleario, como la CUP. Estas realidades cuentan con precedentes históricos en su desarrollo, con distintas etiologías. Algunos están enraizados en proyectos de largo alcance, como Unitat Municipal 9 de Sant Pere de Ribes, ya existente en 1979 (Badia et al., 2018). En otros casos se tratará de nuevas estructuras afianzadas en luchas y significados manejables desde lo político en las nuevas relaciones de biopoder vividas desde lo cotidiano y de las necesidades sentidas. Estas radicalizan la democracia a través de su construcción asamblearia y reticular, combinada de manera horizontal, autónoma y con un alto grado de cohesión y coordinación internas, y que apuntan hacia estrategias de protagonismo social y fuerte crítica de la agenda neoliberal y del poder de los mercados mediante el arraigo local (Subirats, Blanco, Gomà; 2018). Asimismo, es relevante rescatar el hilo conductor del municipalismo social y la actividad vecinal y las luchas locales, dando lugar a plataformas enmarcadas en los denominados "partidos ciudadanía" (Calle y Vilaregut, 2015), que a su vez dan lugar a procesos democráticos de alta intensidad (Barber, 2004) con acento en la deliberación y la coordinación directa.

\section{Hipótesis y objetivos}

Lo expuesto hasta aquí puede interpretarse a la luz de las conclusiones e hipótesis derivadas del principio de subsidiaridad explicitado en la Carta Europea de Autonomía Local de 1989, que permeabiliza la interpretación de la gestión directa de servicios, tal como indican informes como el publicado por la Unidad Internacional de Investigación de Servicios Públicos de la Universidad de Greenwich (Hall, 2012), así como estudios relativos a la gestión del agua en municipios y países, los realizados por Pigeon-Mc Donald, Haedemon y Kishimoto (2013). Se hace una lectura extensa y ampliada del informe del Tribunal de Cuentas de 2011 sobre las condiciones de prestación de los servicios públicos municipales, según los cuales la provisión pública de servicios resulta más eficiente en su expresión local.

Por todo eso, el objetivo general de esta investigación consistirá en una interpretación crítica fundamentada en los principios de la economía política crítica disruptiva con el fin de identificar las prácticas, experiencias y lecciones aprendidas en los Gobiernos municipalistas de larga trayectoria en Cataluña que nos permitan desarrollar diversas estructuras de oportunidad (Tarrow, 1977) para la gobernanza. Estas son la redistribución de funciones y recursos entre Gobiernos centrales y locales, la mejora de la capacidad de autonomía local, el papel de las organizaciones comunitarias, la participación ciudadana, la prestación de servicios e innovaciones en la gobernanza y buenas prácticas. Este análisis se realizará junto con una revisión del pensamiento municipalista contemporáneo, en el que se conjugarán perspectivas del municipalismo libertario de Murray Bookchin, las prácticas propias del confederalismo democrático kurdo en su desarrollo decisional, los principios de participación económica de los modelos de economía participativa de Michael Albert y los principios confederalistas del sindicalismo libertario ibérico.

\section{Metodología}

Para la realización de este trabajo, partiremos de la revisión y selección de referencias bibliográficas relativas al estudio de los distintos enfoques teóricos referentes al municipalismo que nos permitan rehuir de una contraposición antagónica de sistemas y ofrecer una investigación con mayor rigurosidad metodológica respecto el análisis de datos y su sistematización. También para velar por una selección pertinente de documentos que nos permita permeabilizar la elaboración del estudio de una manera fundamentada que eluda sesgos en la identificación y empleo de información (Sánchez; Botella, 2010).

Para ello emplearemos la búsqueda de documentos y datos mediante las plataformas de búsqueda WOS, SCOPUS, Dialnet y Google Scholar, a través del uso de las palabras "municipalismo; radicalización democrática; ecología social y glocalidad". De los 231 documentos finales seleccionados, 23 corresponden a la 
plataforma WOS, 48 a SCOPUS, 37 a Dialnet y 123 a Google Scholar. Al aplicar un segundo proceso de criba que nos conduce a una selección de 35 documentos finales, 4 corresponden a WOS, 7 a SCOPUS, 5 a Dialnet y 19 a Google Scholar. El motivo es generar un análisis comparativo de las diversas políticas públicas, así como una evaluación de impacto y resultados sobre la mejora de la capacidad de autonomía local, el papel de las organizaciones comunitarias y la participación ciudadana, la eficiencia y equidad de la prestación de servicios, e innovaciones en la gobernanza y buenas prácticas.

\section{De la teoría a la práctica}

Para dotarnos de herramientas teóricas y conceptuales para una adecuada interpretación de los fenómenos estudiados, realizaremos una cala teórica e histórica en algunos precedentes que tienen interés para nuestra investigación.

\subsection{Un ejemplo teórico: el caso de Murray Bookchin}

Las diversas prácticas históricas socialistas del confederalismo, además de otras experiencias de carácter libertario, como los comuneros españoles, los revolucionarios americanos, los franceses de Sans-culottes en la configuración de la Comuna de París, así como revoluciones democráticas y otros proyectos revolucionarios que abarcan la revolución española anarquista de 1936, atrajeron la atención de teóricos como el historiador, investigador, ideólogo y activista ecologista estadounidense Murray Bookchin, quien en su análisis registraba un conjunto de movimientos ilegales, iniciativas vecinales y organizaciones no gubernamentales de asistencia social (Bookchin, 1977). De entre todas estas agrupaciones, hacía especial hincapié en los anarquistas del siglo xix, en los que encontró la idea-fuerza de que el comunismo debe desempeñar principalmente un papel administrativo, donde la toma de decisiones es responsabilidad de las asociaciones laborales, grupos de productores, colectivos y cooperativas que configuran la federación. En su obra culmen, Las políticas de la ecología social. Municipalismo libertario (2002), Bookchin proponía una forma de democracia directa compuesta por asambleas autónomas en las que la confederación se instituyera como organismo administrativo con prerrogativas limitadas (1990).

Se materializaba así, a inicios del siglo xxi, un principio teórico que ahonda en el debate público contemporáneo sobre la implementación del gobierno local, como contraposición a la configuración del Estado-nación del siglo xvii, originada con el modelo productivo capitalista, con independencia de un sistema de gobierno central y fundamentado en la autoorganización social. Esta estaba formada por una multiplicidad de asociaciones voluntarias que se enraizaba en las objeciones al autoritarismo de la Unión Soviética en los años 60, aun desde una perspectiva claramente socialista y anticapitalista. Según Bookchin, el municipalismo libertario constituye una de las diversas variedades contemporáneas de socialismo libertario e izquierda antiautoritaria y anticentralista, fundamentada en: 1) el apoyo a la confederación descentralizada de municipios, complementaria a la teoría del geógrafo Christophe Guilluy (2014);2) la oposición al estatismo inspirada en obras como Federalismo, Socialismo y antiteologismo (Bakunin, 1868), entre otros autores; 3) la creencia en la democracia directa, y 4) una visión de la sociedad libertaria-comunista (Bookchin, 1995) que surge como confluencia de los principios teóricos del marxismo y la ecología social, así como de los valores filosóficos del anarquismo colectivista (Biehl, 2007) en el periodo de reconciliación ideológica del movimiento anarquista y comunista tras la caída del muro de Berlín, que dio origen a los principios ideológicos de la New Left de la década de 1970.

Estos planteamientos fundamentados en la ecología social expresan de forma concisa el hecho de que la sociedad no aparece de forma repentina o esporádica en el mundo, en contraposición a una concepción postmoderna de la historia presentada por Eric Hobsbawm (1994) como uno de los grandes males de la sociedad contemporánea. Por ende, la vida social no es necesariamente una confrontación con la naturaleza en un proceso de transformación de esta que las perspectivas productivistas de las corrientes liberales e incluso marxista habían sostenido con anterioridad. Se entiende así el surgimiento de la sociedad como un hecho natural que tiene su origen en la biología de la socialización humana, donde el proceso de socialización humana a partir del cual la sociedad emerge, ya sea en forma de familias, bandas, tribus o tipos más complejos de relaciones humanas, tiene su origen en las relaciones con los padres, en particular la madre y vinculación infantil.

De esta manera, la ecología social de Bookchin, que emplearemos argumentalmente como la síntesis más precisa de prácticas y pensamientos históricamente dados de la acción local directa desde el comunismo y el anarquismo, se divide en dos partes. El naturalismo dialéctico en sus términos metodológicos y ontológicos; y, por otra parte, la filosofía de la historia y el municipalismo libertario relacionado con la política (Bookchin, 2012).

Este concepto se armoniza con las tradiciones teóricas y políticas de autores como John Locke, JeanJacques Rousseau, Immanuel Kant, así como con el socialismo democrático a través del énfasis relativo al potencial transformador del mundo y una sociedad más libre, justa e igualitaria y la posibilidad de procesamiento de la razón inherente a la especie humana. Se arraigan los principios teóricos en diversos críticos de la época moderna temprana: los pensamientos de Rousseau, el anarquismo o teoría crítica de la sociedad, que llevan a 
concluir en una fuerte crítica al capitalismo sobre la reducción de la razón a la racionalidad instrumental centrada en la eficiencia, la mercantilización de las relaciones humanas, los procesos de desposesión y desigualdad fruto de los procesos de concentración y centralización de capital, fuertemente arraigados en el análisis de Karl Marx en Das Kapital y la contaminación del medio ambiente, la crisis ecológica, que amenaza con destruir muchas especies de plantas y animales.

Para Bookchin, las herramientas del capitalismo incluyen procesos de hipermatematización del mundo, la mecanización, el uso de la ciencia y la tecnología para la explotación de la naturaleza, incluida la urbanización, la producción y el consumo en masa, así como la concentración de los centros industriales, la excesiva división del trabajo y la burocracia (Bookchin, 2012:132).

En este sentido, Bookchin relata la revolución social como un largo proceso de toma de control de los municipios y su reconstrucción sobre la base de asambleas barriales, afirmando que "nos enfrentamos a la necesidad no solo de mejorar la sociedad o alterarla; nos enfrentamos a la necesidad de rehacerla" (Bookchin, 2012: 170). Mientras, asevera de forma rotunda que no se puede entender la revolución de manera exclusiva en la política, como juego cotidiano de actores por espacios de poder e influencia, sino también en la polity como función de distribución de poder en la sociedad, abarcando, tal como narra Bookchin, "nuevas formas de pensar y sentir, y una nueva interrelación humana en las relaciones, incluyendo las formas en que experimentamos el mundo natural" (Bookchin, 1990). En otras palabras, argumenta la necesidad de rotura con las relaciones de biopoder establecidas que articula Guy Debord en La Sociedad del Espectáculo (1967).

De esta manera, la revolución se constituye en la creación de un movimiento que confronta una constitución liberal representativa fruto del capitalismo con la figura centralista del Estado-nación mediada. Se aspira a una superación de los conflictos sociales hasta la igualdad de acceso a una vida digna, en la cual la disponibilidad de la democracia devenga colectiva y equitativa.

En este sentido, apunta al resurgir de análisis holísticos de la realidad social originados con la economía política crítica, y los movimientos originarios de estas corrientes teóricas deben emprender, más allá de cambios, acciones que configuren una nueva visión clara y distinta de sociedad libre y ecológica. Deben indicar soluciones a largo plazo, pero también una respuesta adecuada y concisa a los problemas inmediatos, como reafirmación a la dialéctica de Gramsci en relación al dilema del pan y la mantequilla, las necesidades inmediatas y las ideas de largo plazo.

Sobre la idea de la democracia directa en la última fase del municipalismo, Bookchin expone un conjunto de principios y valores de la democracia, la economía municipal, la ecología y la justicia social, y la elección, en tanto a la creación de candidatos para las elecciones locales que actúan bajo el programa de municipalismo libertario con la premisa de obedecer y educar a otros residentes sobre el municipalismo (Heller, 1999). Es un principio desencadenado por los modelos educativos de Francesc Ferrer i Guardia (1912).

Este es el concepto de política democrática, que no incluye la representación voluntaria clásica del parlamentarismo, sino que se arraiga en comunidades de autogobierno directo a nivel local (Bookchin, 1989:132) en las que su elemento principal claudica en un foro democrático para la creación de la voluntad y la opinión del municipio en la que todos los miembros de la comunidad proponen, debaten y determinan soluciones a problemas comunes. La manera en la que se concilian las posiciones en común no es necesariamente el consenso de la manera en la que lo mencionaron autores como John Rawls y Jürgen Habermas, pero sí el voto mayoritario, de tal manera que la administración resulta la aplicación de la toma de decisiones del poder y estructuras cívicas. Tiene una naturaleza limitada y sujeta al control público, en la que el Gobierno se consolida mediante comités o colectivos de personas que fueron seleccionados por un foro democrático (Bookchin, 1989:175).

Por lo tanto, el municipio constituye el modo de vida social, y su gestión a nivel local en vigor, partiendo del principio de libertad del resto de asambleas locales y su confederación, implicaría la misma constitución de los principios ecológicos y sociales.

En este sentido, el concepto político de Bookchin sobre las relaciones intermunicipales incluye la economía como asunto subordinado a la autoridad civil (Bookchin, 1989:188) en las relaciones entre comunidades locales, donde los vínculos regulan el mecanismo de convivencia entre comunidades, que se caracteriza por el beneficio mutuo y combina virtualmente todos los grupos.

El confederalismo como principio de organización social alcanza su pleno desarrollo cuando la economía misma se confedera mediante la colocación de granjas locales, fábricas y otras empresas necesarias en manos municipales locales, es decir, cuando una comunidad, ya sea grande o pequeña, comienza a administrar sus propios recursos económicos en una red interconectada. Forzar a una elección entre una autosuficiencia autárquica, por un lado, o un sistema de mercado de intercambio por el otro es una reducción simplista y una dicotomía innecesaria. Se trata de una distribución entre comunidades de acuerdo con sus necesidades, donde las comunidades se entrelazan en el quid pro quo de las relaciones de intercambio (Bookchin, 1990: 7).

La economía participativa es un concepto que terminaría desarrollando el economista y activista Michael Albert junto al econonomista y activista político autodeclarado como producto del movimiento estadounidense de la década de 1960, Robin Hahnel. Se enmarca en la nueva izquierda, de carácter antiestatista y cercano al socialismo libertario, en la obra publicada en 2003, Vida más allá del Capitalismo. 
Para Albert y Hahnel, la economía participativa o Parecon se presenta como una contraposición colectiva al centralismo de las administraciones estatales en relación a la gestión de bienes desde el monopolio de la información y el modelo autoritario de subordinación que configura la elaboración y gestión de recursos Top down. Ahonda en el debate de lo común como una experiencia colectiva de lo público confrontada al sistema productivo capitalista en tanto un reconocimiento de modelos de competencia sobreproductivos que acarrean, tal como explicaba Henryk Grossman en The Law of Accumulation and Breakdown of the Capitalist System (1929), un proceso inherente de crisis cíclicas y relaciones de consumo antagónicas. Este ocurre dada la amplitud de movimientos de acumulación de capital en el proceso de rentabilidad como diferente al de la amplitud de los movimientos de acumulación de capital en el proceso de trabajo, valorados por el verdadero volumen del aparato de producción. Hace su desproporción un fenómeno constante del sistema productivo capitalista, fruto del doble carácter de su esencia, que supone por un lado el proceso de obtener rentabilidad y, de otro, el del trabajo. Incluso en periodo de depresión, continua el proceso de acumulación y centralización, diferenciándose de un ciclo de hausse por la agudización del fenómeno de interrupción. Contribuye así a la pauperización de las clases desprovistas de medios de producción en los procesos de concentración y centralización de capitales, ejerciendo un monopolio fáctico de la toma de decisiones e información en los estratos más beneficiados. Este sistema presenta prácticas que se remontan a ejemplos paradigmáticos de las colectivizaciones agrarias de Aragón entre 1936 y 1938, o las 315 empresas autorrecuperadas argentinas en 2015.

En resumen, según el confederalismo de Murray Bookchin:

Es sobre todo una red de consejos administrativos cuyos miembros o delegados son elegidos de las asambleas democráticas populares [...]. Los miembros de estos consejos confederales son estrictamente obligatorios, recuperables y responsables de las asambleas que los elijan para coordinar y administrar las políticas formuladas por las propias asambleas. Su función es, pues, puramente administrativa y práctica, no política. Una visión confederalista en una clara distinción entre la formulación de políticas y la coordinación y ejecución de las políticas adoptadas. La formulación de políticas es exclusivamente el derecho de las comunidades populares. Asambleas comunitarias basadas en las prácticas de democracia participativa. Administración y la coordinación son responsabilidad de los consejos confederales, que se convierten en el medio para interconectar pueblos, ciudades, vecindarios y ciudades en confederales redes Así, la energía fluye de abajo hacia arriba en lugar de hacerlo de arriba hacia abajo [...] (Bookchin, 1984:128).

Esto equivale a una revitalización del término griego polis en su sentido más expansivo, transformando su ideal de paideia desde la élite hasta lo igualitario, llegando a afirmar que los municipios confederales son concebidos como contrapeso al poder del Estado-nación generando una tensión entre el localismo y el Estado, dado que estos dos sistemas no pueden coexistir para un largo periodo de tiempo (Bookchin, 1990).

\subsection{Un ejemplo histórico: el caso del Kurdistán occidental}

En los albores de la configuración municipalista de Bookchin, surge el confederalismo democrático arraigado en la proclamación de Abdullah Öcalan el 20 de marzo de 2005, en el que terminan fundamentándose las bases ideológicas del Partido de Trabajadores del Kurdistán. En él se incluyen las concepciones de la ecología social, así como reflexiones de Immanuel Wallerstein en la realización práctica orientada en el modelo del municipalismo libertario de Murray Bookchin, como la que constituye la actual forma de gobierno en Rojava (Kurdistán occidental).

La meta de esta constituye "la organización de una sociedad civil democrática-ecológica en aras de alcanzar una paz estable en el Medio Oriente" (Nilüfer, 2007), con pretensión de superar la existencia de los Estadonación configurados alrededor de la Primera Guerra Mundial. Se configura la coexistencia entre etnias y religiones de distinta región, y el presidente de Kongra Gel (Congreso Popular del Kurdistán), Murat Karayilan, declara como un principio básico "la unidad equitativa y voluntaria" (Nihat; 2007: 175). De esta manera, tal como el EZLN en el estado mexicano de Chiapas desde la década de 1990, la sociedad toma y organiza tareas sociales, culturales y políticas por cuenta propia, limitando de este modo las intervenciones de los Estados a lo estrictamente necesario.

En contraste con "la clásica federación de Estados, el confederalismo democrático aspira a una confederación de estructuras parciales autónomas de una sociedad concreta, como consejos de juventud, mujeres, así como distintos territorios con población kurda", pero a su vez, asociaciones civiles y cooperativas e instituciones sociales (Nihat, 2007: 176).

"Como organización general para dar estructura a esta política, se consolida la Koma Civakên Kurdistan (KCK) o Confederación de Pueblos de Kurdistán con el Congreso Popular del Kurdistán como comité superior" (Nihat, 2007: 185). "La Confederación de los Pueblos de Kurdistán o Unión de las Comunidades es, de esta manera, la organización creada para poner en práctica el confederalismo democrático, en un intento de organizar al pueblo kurdo en todos sus territorios bajo una cierta autonomía sin tocar los Estados-nación ni sus límites territoriales, en los cuales se encuentra la población kurda". Se constituye el KCK mediante consejos y organismos políticos de la sociedad kurda desde una lógica bottom up (Nihat, 2010). 
Por su parte, el Congreso Popular del Kurdistán instituye un paralelismo de parlamento del KCK, formado tras el congreso de octubre de 2003, en el que se reunieron de manera constituyente el Congreso de la Libertad y la Democracia del Kurdistán (KADEK), la Organización de Mujeres y la Organización de Jóvenes y Estudiantes, con Abdullah Öcalan como dirigente de honor. Fue un congreso integrado por un conjunto de 300 personas democráticamente elegidas, y dirigido por la junta ejecutiva y algunas comisiones de distintas áreas, en las que se encuentran tanto el presidente del Consejo Legislativo, actualmente Zübeyir Aydar, como el presidente del Consejo Ejecutivo, Murat Karayılan, y el vicepresidente del Consejo Ejecutivo, Cemil Bayı.

\subsection{La continuidad de los análisis y las experiencias en el caso catalán: una década de experiencias municipalistas}

Estas experiencias se han ido sucediendo en contextos geográficos muy diversos y han tenido incidencia en distintos grados en el contexto municipal catalán. En el marco de Cataluña, desde finales de la década de 1970, diversos procesos plantean la necesidad de que el municipio sea la estructura social donde edificar una nueva democracia verdaderamente popular. Esta toma sus raíces en procesos como Unitat Municipal 9, emergido con las primeras elecciones municipales de 1979 en Sant Pere de Ribes y que actualmente constituye una de las múltiples Candidatures d'Unitat Popular en las comunidades de lengua catalana, consolidada tras la Assemblea Municipal de l'Esquerra Independentista del 14 diciembre del año 1986 en Barcelona. Está arraigado en el término de "unidad popular" originado en la alianza de izquierdas chilena encabezada por Salvador Allende, que impulsó un movimiento de transformación socialista y gobernó hasta el golpe de estado de Augusto Pinochet. El concepto "unidad popular" es de una referencia marxista clara.

Se entiende en términos marxistas cómo "una agrupación de movimientos populares y organizaciones políticas de diferentes sectores de las clases populares anticapitalistas con un programa claro de reivindicaciones concretas. [...] La unidad popular combina la movilización y la desobediencia civil de los sectores populares, junto con la acción institucional yendo más allá de simples agrupaciones electorales, constituyendo la agrupación de todas las fuerzas transformadoras de la sociedad bajo un programa de reivindicaciones concretas, y sin olvidar los elementos políticos generales o estratégicos" (Assemblea Nacional Extraordinaria de la Candidatura d'Unitat Popular, 2009: 28).

Es una organización asamblearia y no jerárquica configurada por un secretariado nacional que instituye el órgano encargado de gestionar el día a día de la candidatura de Unidad Popular y no tiene atribuciones políticas, así como de un súmmum de diferentes asambleas locales, que funcionan de manera autónoma y toman sus propias decisiones mediante su militancia. Están agrupadas en trece asambleas territoriales para coordinarse entre sí y facilitar la toma de decisiones a nivel nacional. Tienen como máximo órgano de decisión la Asamblea Nacional como el conjunto de toda militancia, y es la encargada de aprobar los líneas estratégicas y tácticas a seguir, así como aprobar presupuestos o los nuevos estatutos con una periodicidad mínima anual (Candidatura d'Unitat Popular, 2017).

En municipios catalanes con dimensiones territoriales y poblacionales dispares como Viladamat, Navás y Berga, con un total de 466, 6.171 y, 16.199 habitantes, respectivamemte (INE, 2018), suponen localidades relevantes en la consolidación de estos nuevos agentes políticos, con una mayoría absoluta consolidada durante los últimos diez años.

En ellos observamos prácticas sui generis en la creación de nuevas prácticas inclusivas de participación ciudadana directa y corresponsabilidad como acto constitutivo de ethos público, que resultan paradigmáticamente exitosas en la implementación reglamentaria de consejos del pueblo. Estos participan activamente en la toma de decisiones en general y específicamente en presupuestos y urbanismo, con una participación cercana al 29\% en el conjunto de todos ellos; así como protocolos específicos de servicios de integración laboral (SIL), con el fin de favorecer la inclusión de las personas con diversidad funcional en el ámbito laboral o el Programa de Inserción Laboral. Estos se estructuran de forma interseccional en políticas como la política de vivienda del ayuntamiento de Viladamat.

También se observan grandes pugnas por la municipalización de servicios básicos, como la cuestión de la gestión pública del agua en los tres territorios, entendiéndose como una aspiración a democratizar el acceso al agua y mejorar la eficiencia del servicio. De manera análoga está la cuestión de la ampliación del parque público de vivienda, con la intención de ayudar a generar una regulación sobre la actual especulación del alquiler y el díficil acceso a la vivienda. Todo esto a pesar de los impedimentos de la estructura constitucional del Estado español y su reforma del artículo 135 de la Constitución Española en el año 2011, en el cual el Partido Socialista y el Partido Popular, como fuerzas políticas mayoritarias, establecieron en el texto el concepto de estabilidad presupuestaria y el pago de la deuda pública frente a cualquier otro gasto del Estado en los Presupuestos Generales, incluyendo los presupuestos sociales.

A su vez, encontramos numerosos esfuerzos en la construcción y desarrollo de políticas transversales de carácter feminista para la erradicación de desigualdades y violencias, donde observamos que en todos ellos hay una estrecha colaboración con los tejidos asociativos feministas. También existen concejalías o similares, en- 
focadas al trato del tema de género, así como el impulso de protocolos de prevención de agresiones machistas y LGBTI-fóbicas en fiestas mayores de los municipios y otras actividades de ocio.

\section{Conclusiones}

Aunque de diferentes dimensiones de las diversas tradiciones socialistas, la teorización del municipalismo como objeto de radicalización democrática permeabiliza el conjunto de teorías y prácticas que apuntan a un horizonte enraizado en el republicanismo radical relativo al concepto de libertad de la que el politólogo y filósofo irlandés, Philip Pettit (1997), sostenía que el individuo es libre en tanto no es objeto de interferencias arbitrarias dadas por otros actores en un escenario social e institucional que garantiza esa libertad. El politólogo e historiador Isaiah Berlin (2001: 58) afirmaba querer que su "vida y decisiones dependan de mí mismo, y no de fuerzas exteriores, sean estas del tipo que sean" como una reflexión que pone en el punto de mira las contingencias del modelo productivo capitalista en un proceso de desposesión y trabajo asalariado, así como las de un Estado centralizado y autoritario. Así obligaba a concebir, como explicaba él mismo en Dos conceptos de libertad, la imposibilidad de configurar una libertad individual universal sin estructuras colectivas que garanticen la igualdad en sus términos sociales y colectivos. Es una línea apuntalada en los análisis en los procesos de toma de decisiones que, incluso transcendiendo las líneas analíticas marxistas, investigadores como Dunleavy y O'Leary explican desde ópticas neopluralistas sobre la posición de privilegio de los grupos empresariales y el mercado frente al súmmum de la sociedad (1987: 275). Todo ello en una economía de mercado capitalista en la que las decisiones respecto a la inversión y el empleo, a pesar de ser objeto de interés general, no están sujetas en cualquier caso a control democrático (Lindblom, 1977: 172), lo que ocasiona un proceso decisional dual frente a problemas secundarios y una impermeabilidad de los problemas de primer orden referidos a la estructura económica y el uso y distribución de los medios de producción.

A su vez apuntan a un proceso que transgrede las barreras de la configuración ética del sentido de lo común en una estructuración estrictamente administrativa, de la cual se han dado referencias a lo largo del territorio catalán. Se comprende la singularidad de lo común no como una tercera vía entre el mercado y lo público, sino como un proceso de democratización del último, donde la particularidad de la cual difieren es la gestión per se, dada por una administración central frente a un proceso de democratización. De ello se puede tomar como referencia municipios como Navas, y no el sujeto titular del bien, que es en ambas instancias el conjunto de la sociedad con derecho a uso y disfrute de la misma.

Es en este sentido que el municipalismo constituye una alternativa política y social que señala las contradicciones del modelo productivo capitalista y su superación; a la par que profundiza en los principios de libertad y participación en su sentido más radical y extensivo desde los núcleos más cercanos a las cotidianidades vividas de la sociedad en su conjunto. Responde a las necesidades emergidas mediante las contradicciones entre la racionalidad histórico política dominante y la deflación de poder y pérdida de apoyo a los partidos de régimen constitutivo. Ello a raíz de la crisis económica y el devenir de nuevas conductas de carácter colectivo vinculadas a nuevos sujetos políticos asociados a la participación directa como símbolo de la "regeneración democrática", subjetivamente vinculada a la percepción de un sistema de oligarquía en la economía y política.

Desarrollando un proceso de planificación participativa no necesariamente contraria al mercado, en la junta facilitadora de producción se determinan los precios indicativos de los diferentes bienes que se pueden producen. Las federaciones de consumo manifiestan sus necesidades de consumo en aras de una producción no expansiva y sostenible y en las que las federaciones de trabajadores emiten su propuesta de producción para evaluar las propuestas de consumo, tanto en su coste e impacto social, ajustando las protestas de ambas federaciones, eludiendo excesos de oferta como sobreproducción y demanda como escasez.

Es una alternativa que aprovecha la capacidad de incidencia a través del ámbito local y su articulación propia arraigada al territorio para incidir en la política no solamente nacional, sino municipal. Pone la acción local como un núcleo de articulación que abre la ventana a marcar el municipalismo como superación de la lógica Estado-nación que requiere de por sí la ruptura frontal con el Estado Español y la concepción nacional del régimen constitutivo del 78. Se democratizan los espacios locales y las estructuras administrativas de la ciudad y ofrecen un punto de reconciliación y trabajo dentro del amplio sector asociativo socialista, como una alternativa al conflicto territorial actual entre Catalunya y el conjunto de naciones que lo constituyen.

\section{Bibliografía}

Albert, M. (2012): “Asignación Participativa”, ZCom. Disponible en: http://web.archive.org/web/20130411160226/http:// zinternational.zcommunications.org/Spanish/parecon08.htm [Consulta: 11/3/2016].

Albert, M. (2012): “La economía y el resto de la sociedad”, ZCom. Disponible en: http://web.archive.org/web/20130411160226/ http://zinternational.zcommunications.org/Spanish/parecon10.htm [Consulta: 11/3/2016].

Albert, M. (2012): "Larga vida a una parte del marxismo", ZCom. Disponible en: http://web.archive.org/web/20120301182751/ http://zinternational.zcommunications.org/Spanish/1003albert2.htm [Consulta: 11/3/2016]. 
Albert,M.(2012): “Unprogramapara conseguirla auto-gestión”,Zcom.Dispobileen:http://web.archive.org/web/20130411160226/ http://zinternational.zcommunications.org/Spanish/parecon05.htm [Consulta: 11/3/2016].

Albert, M. (2012): “Un programa para conseguir una asignación participativa de los recursos”, ZCom. Disponible en: http://web. archive.org/web/20130411160226/http://zinternational.zcommunications.org/Spanish/parecon09.htm [Consulta: 11/3/2016].

Albert, M. (1997): “Autogestión”, Zcom. Disponible en: http://web.archive.org/web/20130411160226/http://zinternational. zcommunications.org/Spanish/parecon04.htm [Consulta: 11/3/2016].

Albert, M. (2001): "El movimiento por una economía participativa. Una introducción”, ZCom. Disponible en: http://web.archive. org/web/20130411160226/http://zinternational.zcommunications.org/Spanish/parecon01.htm [Consulta: 11/3/2016].

Albert, M. (2005): Parecon. Vida después del capitalismo, Tres Cantos, Akal Ediciones.

Anderson, P. (1979): Considerations on Western Marxism, Madrid, Editorial Siglo XXI.

Andreu, M. (2016): Ciutats invisibles. Viatge a la Catalunya metropolitana, Barcelona, L'Avenç.

Arias, F. (2000): Desigualdad urbana en España, Madrid, Ministerio de Foment.

Atentas, J. M. (2013): "La indignación, tras la explosión inicial. El 15M en Catalunya durante 2012", Anuari del Conflicte Social, $\mathrm{n}^{\circ} 2: 263-264$.

Auge, M. (1992): Los no lugares. Antropología sobre la modernidad, Barcelona, Editorial Gedisa.

Bayona, J. (2007): “La segregación residencial de la población extranjera en Barcelona. ¿Una segregación fragmentada?”, Scripta Nova, Revista Electrónica de Geografía y Ciencias Sociales, 235, nº 11:1-32.

Bettin, G. (1982): Los sociólogos de la ciudad, Barcelona, Editorial Gustavo Gili.

Berlin, I. (2001): Dos conceptos de libertad y otros escritos, Madrid, Alianza.

Bonet, J. (2012): "El territorio como espacio de radicalización democrática", Athenea Digital, 12: 15-28.

Bookchi, M. (2009): Las políticas de la ecología social, Municipalismo libertario, Barcelona, Virus.

Bosch, J. (2008): "Integració i mobilitat residencial de la población immigrada a Catalunya", en Les condicions de vida de la población immigrada a Catalunya, pág. 107-136, Barcelona, Fundació Jaume Bofill.

Burbano, F. A. (2013): "Las migraciones internas durante el franquismo y sus efectos sociales: el caso de Barcelona", Memoria de investigación, Universidad Complutense de Madrid.

Buzar, S. B; P. Odgen y R. Hall (2005): "Households matter: the quiet demography of urban transformation", Progress in Human Geography n 29: 413-436.

Capel, H. (2002): La morfología de las ciudades, Vol. 1: Sociedad, cultura y paisaje urbano, Barcelona, Ediciones del Serbal.

Capel, H. (1975): Capitalismo y morfología urbana en España, Realidad

Geográfica.

Carreras, C (2013): La ciudad en la literaruta, Lleida, Editorial Milenio.

Carreras, C., A. Morcuende, S. Martínez Rigol y L. Frago (2015): “Cities, public space and citizenship: some contemporany mediterranean urban social movements", Atenas: Annual Internacional Conference on Earth, Geology and Geography.

Castells, M. (2012): Redes de indignación y esperanza, Alianza Editorial, Madrid.

Calle Collado, A. (2005): Nuevos Movimientos Globales, Hacia la radicalidad democrática, Madrid, Editorial Popular.

Calle Collado, A. (2013): La transición inaplazable. Los nuevos sujetos políticos para salir de la crisis, Barcelona, Icaria.

Calle Collado, A, R. Vilaregut Sáez (2015): Territorios en democracia. El municipalismo a debate, Barcelona, Icaria.

Casassas, D. (2015): "Indignation and Claims for Economic Sovereignty in Europe and the Americas: Renewing the Project of Control over Production", en

P. Wagner (ed.), African, American and European Trajectories of Modernity. Past Oppression, Future Justice?, Edinburgh: Edinburgh University Press, pp. 258-287.

Casassas, D. (2019): "De que parlem quan parlem de república”, Catarsi Magazin, núm. 2, pp. 10-10.

Champion, T. (2001): "Urbanization, Suburbanization, Counterurbanization and Reurbanization", en PADDISON, Ronan, Editorial, Handbook of Urban Studies. London, SAGE, pp. 143-161.

Choay, F. (1994): "El reino de lo urbano y la muerte de la Ciudad", en Martín,

A. 2004, Lo urbano en 20 autores contemporáneos, Barcelona, Edicions UPC, pp. 61-72.

Constant, B. (1989): De la libertad de los antiguos comparada con la de los modernos, Escritos políticos, Madrid, CEC.

Costa, M y S. Porcel (2013): "L'estructura socioespacial de la regió metropolitana de Barcelona des d'una aproximació multimètode. Una proposta metodològica per a l'estudi de la diferenciació socioresidencial”, Documents d'Anàlisi Geogràfica 2013, vol. 59, no 2 315-345.

Clark, W., Onaka (1983): “Life Cycle and Housing Adjustment as Explanations of Residential Mobility”, Urban Studies, vol. 20 $\mathrm{n}^{\circ} .1:$ : 47-57.

Cruells, M. y P. Ibarra (2013): La democracia del futuro: del 15M a la emergencia de una sociedad civil viva, Barcelona, Icaria.

Domènech, X. (2014): “Asaltando muros. De movimientos sociales a movimientos sociopolíticos", Iglesia viva: revista de pensamiento cristiano, ISSN 0210-1114, No. 259: 21-34.

Erdozaia, A. I. (1992): "Los valores básicos de una sociedad y el desarrollo comunitario", Pedagogía Social. Revista Interuniversitaria, 7: 99-128.

Engels, F. (1964): Anti-Düring. La Subversión de la ciencia por el sueño Eugen Dühring, México D.F., Editorial Fondo de Cultura Económica.

Erdozaia, A. I. (1992): "Los valores básicos de una sociedad y el desarrollo comunitario", Pedagogía Social. Revista Interuniversitaria, 7: 99-128.

Errejón, I. (2015): "Pateando el tablero: El 15M como discurso contrahegemónico cuatro años después", Encrucijadas: Revista Crítica de Ciencias Sociales, N. 9.

Errejón, I. (2011): “El 15m como discurso contrahegemónico”, Encrucijadas. Revista Crítica de Ciencias sociales, 2: 120-145.

Etxezarreta, M y R. Ribera (2008): “Auge y crisis de la vivienda en España”, Informes de economía no 5. Seminario de economía crítica TAIFA.

Estefanía, J. (2009): Informe sobre la Democracia en España 2009. Hacia un New Deal global, Madrid, Fundación Alternativas. 
Estefanía, J. (2011): Informe sobre la Democracia en España 2011, Madrid, Fundación Alternativas.

Esteve Pardo, J. (2018): Lecciones de Derecho administrativo, Madrid, Ediciones Jurídicas y Sociales.

Fernández Buey, F. (1978): Ensayos sobre Gramsci. Barcelona, Materiales.

Fontana, J. (2014): La formació d'unaidentitat. EUMO, Barcelona.

Galafassi, G. "Teorías diversas en el estudio de los movimientos sociales. Una aproximación a partir del análisis de sus categorías fundamentales", Movimientos sociales, 11: 7-32.

Gasca, J. (2017): Espacios del consumo y el comercio en la ciudad contemporánea, México, Universidad Nacional Autónoma de México e Instituto de Investigaciones Económicas.

Guilluy, C. (2014): La France périphérique, Paris, Flammarion.

Harvey, D. (2013): Ciudades rebeldes. Del derecho a la ciudad a la revolución urbana, Madrid, Akal.

Harvey, D. (1977): Urbanismo y Desigualdad Social, Madrid, Siglo XXI.

Hobbes, T. (1983): Leviatán, Madrid, Sarpe.

Ibarra Güell, P. (2018): Nuevos movimientos sociales. De la calle a los ayuntamientos, Barcelona, Icaria.

Katarobo, J. (2004): Descentralization and Local Autonomy for Participatory Democracy.

Laclau, E. (2005): La razón populista. Buenos Aires, Fondo Cultura Económica.

Laclau, E., C. Mouffe (1987): Hegemonía y estrategia socialista. Hacia una radicalización de la democracia, Madrid, Siglo XXI.

Lapuente, V. (2011): "Por qué la corrupción no se castiga", The Quality of Government Institute University of Gothenburg.

Pastor, J. (2014): "El 15 M, las mareas y su relación con la política sistémica. El caso de Madrid”, Anuario Del Conflicto Social, $n^{0} 3: 224-247$.

Linde Paniagua, E. (2014): “La crisis del régimen constitucional”, Teoría y realidad constitucional, No 34, 2014, págs. 679-681.

Locke, J. (1999): Segundo tratado sobre el gobierno civil, Madrid, Biblioteca nueva.

Madrilonia (2011): La Carta de los Comunes. Para el cuidado y disfrute de lo que de todos es, Madrid, Traficantes de Sueños.

Martín, A., P. López-Roldán y O. Molina (2011): “Movilidad ascendente de la inmigración en España. ¿Asimilación o segmentación ocupacional?", Papers, 96, no 4 1335-1362.

Martí, M. y J. Bonet (2008): "Los movimientos urbanos: de la identidad a la glocalidad", Actas del X coloquio de Geocrítica.

Mainer, J. C. (2006): "La cultura de la transición o la transición como cultura”, La Transición, treinta años después / coord. por Carme Molinero Ruiz, págs. 153-172.

Manjavacas, J. M. (2017): “Ciclo de movilizaciones sociales, demandas urbanas y nuevos municipalismos. El caso de la Asamblea Ciudadana Ganemos en la ciudad de Córdoba, Andalucía".

Mc.Adam, D., J. D. McCarthy y M. N. Zald. (1999): “Oportunidades, estructuras de movilización y procesos enmarcadores: Hacia una perspectiva sintética y comparada de los movimientos sociales", 21-46.

Morcuende, A. (2018): Rupturas Urbanas. Análisis de las relaciones entre la morfología urbana y la estructura social en la Barcelona contemporánea.

Mocca, E. (2015): “The Politics of Transnational Municipalism for susteintable Developmen in the European Union. An urban analysis".

Mundó, J. (2019): “Soberanía. Un concepte modern”, Catarsi Magazin, núm. 2, PP. 18-26.

Muixi, Z. (2003): El espacio público: ciudad y ciudadanía, Electa.

Muixi, Z. (2004): Elemental, reflexiones en torno a la vivienda mínima, Barcelona, Edicions ETSAB.

Muixi, Z. (2004): La arquitectura de la ciudad global, Gustavo Gili.

Muixi, Z. (2007): Sota les llambordes, la platja, Barcelona, Ediciones Eumo.

Muixi, Z. (2011): Habitar el presente: herramientas para la vivienda del siglo XXI.

Muixi, Z. (2018): Mujeres, casas y ciudades, Barcelona, DPR.

Navarro, C. (2008): "Estudio sobre participación local (CIS 2661)", Boletín CIS, 3.

Navarro, C. (1998): “Globalización y localismo: nuevas oportunidades para el desarrollo”, Revista de fomento social, $209:$ 31-47.

Observatori Metropolità De Barcelona (2014): Comuns urbans a Barcelona. Pràctiques de defensa, cura, reapropiació i gestió comunitària, Barcelona.

Observatori Metropolità de Barcelona i Fundación de los Comunes.

Öcalan, A. (2005): Declaration of Democratic Confederalism in Kurdistan.

Offe, C. (1988): Partidos políticos y nuevos movimientos sociales, Madrid, Editorial Sistema.

Ortega, E y J. Peñalosa (2013): “Algunas reflexiones sobre la economía española tras cinco años de crisis”, Documentos Ocasionales, № 1304. Banco de España.

Ovejero, F. (2001): Democracia liberal y democracias republicanas. Para una crítica del elitismo democrático. Claves de razón práctica.

Parsons, T. (1999): El Sistema Social, Madrid, Alianza Editorial.

Pettit, P. (2006): Republicanismo: una teoría sobre la libertad y el gobierno, Madrid, Losada.

Pisarello, G. (2014): "Proceso constituyente y ruptura democrática: el regreso de un espectro" y "Procesos reconstituyentes y democratización sin fin”, en Procesos constituyentes. Caminos para la ruptura democrática, Madrid, Trotta.

Súarez, O, A. Martínez, B. García y S. Palacio (2018): “Claves para el éxito de la participación comunitaria: diálogos sobre participación en el ámbito local. Informe SESPAS 2018”.

Subirats, J. (2019): "Movimientos sociales y esfera local. La proximidad como espacio de protección y emancipación”, Desacatos: Revista de Ciencias Sociales, núm. 61, págs. 162-169.

Subirats, J. (2018): "El nuevo municipalismo: derecho a la ciudad y comunes urbanos", Gestión y análisis de politicas públicas, núm. 20, págs. 14-28.

Subirats, J. (2013): "Descentralización del sector público y protección social”, Presupuestos y Gastos Públicos, núm. 71, págs. 143-151.

Tapia, L. (2009): “Lo político y lo democrático en los movimientos sociales”, Democracia y teoría política en movimiento, Bolivia, Muela del Diablo/CIMSA, La Paz. 
Tellería, I. (2014): “Crisis de la gobernanza urbana y gestión de los comunes”, RIPS. Revista de Investigaciones Politicas y Sociológicas, 13, núm. 1: 33-47.

Tellería, I. (2016): "Movimientos urbanos y democratización en la ciudad. Una propuesta de análisis”, Asociación Española de Ciencia Política y de la Administración, Núm 40: 91-115.

Thompson, E. P. (2012): "La cultura radical”, en La formación de la clase obrera en Inglaterra, Madrid, Capitán Swing. Wallerstein, I. (1997): El futuro de la civilización capitalista, Barcelona, Ica. 